\title{
O FEMINISMO LATINO-AMERICANO, CARTOGRAFIA PRELIMINAR ${ }^{1}$
}

\section{El feminismo latinoamericano, cartografia preliminar}

\author{
María Luísa FEMENÍAS \\ Universidad Nacional de La Plata \\ mlfeme@yahoo.com.ar \\ https://orcid.org/0000-0003-1144-1197 \\ Tradução de Letícia Pilger DA SILVA \\ Universidade Federal do Paraná \\ leticiaspilger@gmail.com \\ https://orcid.org/0000-0002-1999-7336 \\ Sueliton de Oliveira SILVA FILHO \\ Universidade Federal do Paraná \\ seul.literato92@gmail.com \\ https://orcid.org/0000-0001-7740-794X
}

\begin{abstract}
RESUMO²: O objetivo deste artigo é apresentar um panorama dos feminismos latino-americanos considerando suas diferenças, as experiências compartilhadas nos diversos contextos, assim como a viagem das teorias feministas na região, por meio da ressignificação dos conceitos e da concretização de novas práticas. Primeiramente, serão problematizadas as origens dos feminismos na América Latina. Em seguida, serão analisados trabalhos de feministas latino-americanas que criam conceitos e pesquisam a partir da América Latina como lócus da enunciação e do feminismo como perspectiva, como a fronteira de Gloria Anzaldúa, a criptografia da violência de gênero de Rita Segato, as figuras da virgem-mãe e do huacho de Sonia Montecino, e as identificações fraturadas pelos atravessamentos de gênero e raça de Marie Ramos Rosado. PALAVRAS-CHAVE: feminismo latino-americano; genealogia; gênero; raça; violência.
\end{abstract}

RESUMEN: El propósito de este artículo es presentar un panorama de los feminismos latinoamericanos considerando sus diferencias, las experiencias compartidas en los diferentes contextos, así como el recor-

\footnotetext{
${ }^{1}$ Publicação original: FEMENÍAS, Maria Luisa. El feminismo latino-americano, cartografia preliminar. Pasajes: Revista de pensamiento contemporáneo, Universitat de València, no.19, 2006, n.10, pp.45-53.

${ }^{2} \mathrm{O}$ original não conta com resumo, tendo sido feito pelos tradutores.
} 
rido de las teorías feministas en la región, a través del replanteamiento de conceptos y de la realización de nuevas prácticas. Primero, se cuestionarán los orígenes de los feminismos en América Latina. Luego, se analizarán trabajos de feministas latinoamericanas que crean conceptos e investigan desde América Latina como locus de la enunciación y del feminismo como perspectiva, como la frontera de Gloria Anzaldúa, la encriptación de la violencia de género de Rita Segato, las figuras de la virgen madre y el huacho de Sonia Montecino, y las identificaciones fracturadas por los cruces de género y raza de Marie Ramos Rosado. PALABRAS CLAVE: feminismo latinoamericano; genealogía; género; raza; violencia.

\section{INTRODUÇÃO}

O objetivo deste breve trabalho é mostrar alguns fragmentos do complexo tabuleiro de xadrez que é a América Latina, e, consequentemente, seus feminismos. Contudo, apesar de suas diferenças, tanto geográficas quanto econômico-culturais, algumas vozes e reivindicações se unem a partir de determinadas experiências compartilhadas. Algumas pouco felizes, como é o caso da violência. Fato não menos importante quando se considera que a maior parte de nossos países padeceram de profundas e dolorosas descontinuidades institucionais, das quais não ficaram marginalizadas nem a prática do feminismo ou o movimento de mulheres em geral, como também a reflexão teórica em particular (FEMENÍAS, 2005a). Para todos os países da América Latina, é necessário reconhecer, em maior ou menor proporção, a debilidade ou a juventude de nossas democracias devido a fatores externos e internos - e, por isso, é preciso levar em conta como a política e os desenvolvimentos teóricos feministas recuperam essa experiência enquanto, para adotar um conceito de Ana Bidegain, revelam a capacidade de resiliência das mulheres, ou seja, sua força e sua atitude para enfrentar as diferentes formas de violência econômica, territorial, legal, simbólica, física e moral, oferecendo alternativas positivas mesmo nas piores circunstâncias (BIDEGAIN e OSPINA, 2005).

No geral, sobre os grandes movimentos de mulheres mais ou menos espontâneos, as correntes feministas se tensionam entre Iluminismo-pós-modernidade, universalismoparticularismo, estruturalismo-pragmatismo, modelos da filosofia continental e da estadunidense. No entanto, nem as teorias nem as práticas permanecem à margem de sua recuperação localizada. Nesse sentido, a movimentação/tradução/apropriação das teorias - nunca ingênua - permite marcar coincidências, dissidências e autoctonias. Ao mesmo tempo, apropriam-se do feminismo estadunidense e da potência de um feminismo 
ilustrado ${ }^{3}$, como o de Cèlia Amorós, aos quais mais recentemente se soma a crítica pósestruturalista francesa. No perambular pelos territórios latino-americanos, todas essas teorias foram transformadas, enriquecidas, revitalizadas e encarnadas (LIMA COSTA, 2002), constituindo um solo heterogêneo e frutífero. A meu ver, é relevante que o feminismo tenha se instalado na América Latina como uma contracultura que permeia as estruturas sociais, sobretudo as de resistência.

Precisamente por isso, emergem ao menos duas vertentes: uma potente ressignificação dos conceitos e um conjunto de práticas novas e efetivas. É válido observar que ambas estão de mãos dadas e que sua diferenciação se deve apenas à análise (FEMENÍAS, 2005b). No princípio, as mulheres acumularam um capital simbólico próprio graças a processos múltiplos de apropriação e ressignificação. Se, como afirmou Cèlia Amorós, "a retórica ocidental da emancipação, da autonomia, e de outras coisas semelhantes, é e continua sendo, no infinito jogo de ressignificações, uma adequada e eficaz aliada à luta das mulheres", nas mãos das mulheres latino-americanas essa estratégia tem forte incidência (AMORÓS, 1996, p. 18-19). Prova disso é a forma como traçaram um dos caminhos mais árduos, os períodos de interrupção da democracia, nos quais boa parte de sua energia foi canalizada não apenas para a reivindicação de seus próprios direitos, mas os dos cidadãos em geral.

Tendo isso em vista, toda discussão internacional sobre o feminismo na América Latina precisa responder pelo menos a dois desafios: 1) o que é uma ideologia estrangeira; isto é, importada da Europa ou dos Estados Unidos em tempos relativamente recentes, e 2) que não foi feita nenhuma contribuição significativa porque na verdade apenas permanece marginalizada pelas correntes internacionais (OLIVER, 2002, p. 41). A primeira questão remete ao problema da origem e a segunda ao da importância - no caso de que exista - de suas contribuições. ${ }^{4}$ Convenhamos que "origem" tem pelo menos uma dupla acepção, como começo cronológico (que apresentaremos na primeira seção) e como motivação ou interesse. No primeiro sentido, poderíamos recorrer a um conjunto contundente de argumentos filosóficos (que vão de Nietzsche a Butler, passando por Foucault e Deleuze) para elencar as dificuldades e inconveniências de se invocar noções como "primeiro" ou "origem". Poderíamos inclusive denunciar os pudenda origa com Cèlia Amorós, na tentativa de as feministas construírem genealogias (no geral cooptadas

\footnotetext{
${ }^{3}$ Termo proposto por Célia Amoròs para fazer referência ao feminismo hegemônico que se originou na Europa com o Iluminismo, antes das sufragistas, e que tinha como objetivo a emancipação das mulheres a partir dos ideais iluministas de liberdade e igualdade. (N. dos T.).

${ }^{4}$ Outra versão pode ser consultada em "Aportes del feminismo Iberoamericano", Montevidéu, Centro Cultural España, novembro, 15, 2005.
} 
para as mulheres), enquanto se opõem à busca da origem. Como sustenta Foucault, o genealogista necessita da história para evitar tal quimera (FOUCALT, 1976, p. 8-11) para, consequentemente, concluir que a pergunta pela "origem" se dá apenas por uma ficção ideológica, mais simbólica que real. Contudo, é importante ressaltar que os centros hegemônicos não apenas se perguntam repetidamente pela origem, assim como a evocam como uma "primogenitura simbólica", à maneira de um princípio legitimador. Isso significa que - embora seja um constructo simbólico - a reivindicam ao mesmo tempo que a desqualificam.

Independentemente, as feministas estadunidenses invocam, como se sabe, a Convenção Seneca Falls (1848) como seu ponto de partida de nascimento simbólico. As francesas, a Declaração de Olympe de Gouges sobre os Direitos das Mulheres e das Cidadãs (1793). Na América Latina, poderíamos apresentar a mexicana Juana Inés de la Cruz (1651-1695), figura sem comparação na metrópole imperial, como a primeira feminista da América, de acordo com Octavio Paz. Décima Musa, como foi denominada desde o século XVII, que se autoafirmou - e por extensão afirmou todas as mulheres na posição de sujeito -, sobretudo quando elaborou, em 1691, sua famosa Respuesta a Sor Filotea (ZANETTI, 1995, p. 51). Se foi uma expoente máxima, não foi a única nem permaneceu sem herdeiras.

A respeito da “origem”, entendida como motivação ou interesse, Petrona Rosende já encabeçou na sua revista La Aljaba (Buenos Aires, 1830) a reivindicação de educação e de direitos para as mulheres como ato de justiça. Mais tarde, Juana Manso, em Album de Señoritas, anuncia de forma simples:

Todos os meus esforços serão direcionados à educação das minhas compatriotas e serão voltados ao único propósito de emancipá-las das preocupações torpes e vencidas que proíbem até hoje que façam uso de sua inteligência, privando-as de sua liberdade e até de sua consciência para autoridades arbitrárias [...] quero provar que a inteligência da mulher, longe de ser um absurdo, um defeito, um desatino ou um crime, é seu melhor 'adorno', sua verdadeira fonte de virtude..." (MANSO, 1854, pp. 1-2)

Com clareza e precisão, Manso define a origem de sua luta com motivos e razões suficientes (BATTICUORE, 2005; IGLESIA, 1993).

Não parece admissível, portanto, a acusação de que nós, feministas da América Latina, apenas viemos somar recentemente a uma "moda" estrangeira, mostrando assim mais uma característica de nossa colonização cultural. Nada há de alheio nas reivindicações das mulheres da América Latina. Trata-se muito mais de uma longa tradição constantemente Revista X, v. 16, n. 1, p. 224-238, 2021. 
renovada que se alimenta da própria experiência de um movimento/translação/tradução e apropriação enriquecida de teorias (LIMA COSTA, 2002: 190). Os fundamentos teóricos que mencionamos antes são situados, ou seja, ao abandonarem seus contextos originários e se incorporarem aos nossos se enriquecem em um processo hermenêutico de tradução cultural, de jogos interpretativos (re)criativos, fundamentais para sua sobrevivência. Isso explica também porque no século XIX o feminismo não foi um fenômeno circunscrito no México ou na Argentina, mas se estendeu por toda a extensão da América Latina (BATTICUORE, 1999), porque, dentre outros fatos, a ideia de América Latina como "Pátria Grande" não admitia as fronteiras atuais entre nossos países. Logo, com guerras de independência e de seu ideal libertário, um conjunto notável de mulheres reivindicou seus direitos e esperou em vão que "os ilustres homens criadores da pátria" as reconhecessem como cidadãs e iguais (APONTE, 2005, p. 123-156; MASIELO, 1994, SCHUTTE, 1993), de forma que as guerras civis, as invasões, a fome, as ditaduras as obrigaram a se organizar e a resistir (BIDEGAIN e OSPINA, 2005, p. 157).

A problemática das contribuições do feminismo da América Latina - nossa segunda seção - requer também muitas precisões que, por questões de tempo e espaço, não é possível tratar agora. Apenas como um alerta, convém ter em mente, por um lado, um conjunto de questões vinculadas à equifonia, o logos com autoridade e a credibilidade equivalente (SANTA CRUZ, 1992, p. 147), que, organizados em redes de poder hegemônico, impedem ou, pelo menos, diminuem a importância do feminismo na América Latina, tecendo - talvez - um véu que leva ao seu desconhecimento. Por outro lado, e não menos importante, está o problema que se vincula às cronologias vigentes que respondem a processos de realidades histórico-sociais diversos e politicamente hegemônicos. Nossas "ondas" feministas obedecem a certos ciclos próprios, que às vezes pouco têm a ver com os ritmos que costumam dar legitimidade às periodizações internacionais (FEMENÍAS, 2005c). Seguindo nossas pulsações localizadas, e nem sequer válidas para a América Latina como um todo, nossa experiência feminista tem sido - a respeito das classificações canônicas - de vanguarda ou marginalizada, mas sempre limitada ou cancelada por uma construção de conjunto que muitas vezes fez da América Latina uma entidade homogênea entre exótica e promissora (FEMENÍAS, 2002, p. 56). Essas marcas estão presentes em boa parte da bibliografia atual das feministas latino-americanas, porque o que as sufragistas do século XIX proclamaram com otimismo iluminista em muitos casos ainda não se cumpriu totalmente aqui. Mas deixemos de lado esse espinhoso e complexo terreno.

Desde então, também foram legitimadas práticas feministas que demarcaram novos significados, em cuja visibilidade não podemos aprofundar agora, mas que dão 
conta de um processo de integração amplo, gradual e apoiado tanto no movimento de mulheres como no feminista, com marcas profundas impossíveis de negar como pano de fundo do agir cotidiano. A partir dessa dupla operação teórico-prática, o feminismo latino-americano tem dado contribuições significativas. Faço esse destaque porque mesmo quando no geral o Primeiro Mundo (em especial o anglofalante) projeta sobre nós suas categorias nos heterodesignando como dependentes, exóticas, mais próximas da natureza, pouco confiáveis, naïves ou simplesmente inferiores, nós podemos responder a partir de um locus inesperado. Precisamente, este locus inesperado, este lugar no qual não se espera que estejamos, nos inscreve - nos termos de Butler - como sujeitos-agentes.

Em suma, o feminismo latino-americano tem algo para dizer com sua própria voz. Diante da impossibilidade factual de historiar como um todo nessas páginas o feminismo da América Latina, e até mesmo de traçar suas linhas mais relevantes, sejam teóricas ou práticas, me limitarei a oferecer uns poucos exemplos. Portanto, mencionarei algumas contribuições cuja novidade está no sentido mesmo da ressignificação, o que constitui por si uma apropriação/contribuição interessante a outros tantos conceitos tradicionais. O primeiro é a elaboração da fronteira de Gloria Anzaldúa. Em seguida, o criptograma da violência na análise de Rita Segato. Em um terceiro momento, a figura do huacho tal como a desenvolveu Sonia Montecino, em relação à figura da virgem-mãe. Por fim, o atravessamento da categoria de gênero com a de etnia problematiza a relação de mulheres de cor com sua própria história, fraturando identificações, tal como mostra a análise de Marie Ramos Rosado.

Propositalmente, escolhi teóricas de diversos países de origem e de residência, apesar de o mapa ser incompleto devido a limitações que já indicamos. Também não me deterei no problema da ressignificação das práticas pelas mesmas razões. Apenas para apresentar minimamente sua importância, basta que eu mencione a ressignificação da noção de "maternidade" com as Mães da Praça de Maio (DOMÍNGUEZ, 2005), o Movimento Colombiano de Mulheres pela Paz (BIDEGAIN, 2005) e as mulheres de Nossas Filhas de Regresso à Casa de México (SEGATO, 2005). Impossível separar - como acontece nesses exemplos - o movimento feminista do de mulheres a despeito das dificuldades de articulação, porque, apesar de nem sempre estarem relacionados harmoniosamente, eles têm visibilizado conjuntamente o potencial que as mulheres da América Latina mantêm por séculos. Como afirma Flora Tristán, "Vocês, homens, começam a compreender que fazem um escarcéu antes de tentar analisar a razão do porquê eu reclamo direitos para a mulher?" (UNIÓN OBRERA, 1843). 


\section{DIALÉTICA DA FRONTEIRA}

Como bem sinalizou Amorós, as ressignificações são um tema político. A análise da mexicana Gloria Anzaldúa da fronteira, como lugar de síntese e ressemantização, segue nesse sentido (ANZALDÚA, 1987). Sabemos que, na tradição latino-americana, a fronteira recebeu importantes leituras que se movem sobre o eixo civilização-barbárie, ou, em outras palavras, brancos-índios. Anzaldúa redefine o problema sobre um eixo duplo: homens-mulheres e chicanos-anglo-saxões, em uma hermenêutica transcultural que permite esclarecer o significado múltiplo do lugar das chicanas na fronteira mexicanoestadunidense. Desafiando demarcações políticas, linguísticas, religiosas, econômicas e simbólicas, ela se opõe à leitura da fronteira como uma linha divisória clara que separa dois âmbitos diferentes: o de anglo-saxões/nas e chicanos/as.

Para Anzaldúa, a fronteira é muito mais. O deserto de Chihuahua se estende por ambos os lados da linha imaginária que separa o México do grande país do norte (sic). Não apenas divide ricos de pobres, brancos de mestiços, segurança de insegurança, inglês de espanhol, protestantes de católicos, poder hegemônico de subalterno. The border-a fronteira é o espaço de gestação e produção dos novos significados do Spanglish, porque a fronteira não é um limite rígido que impede a passagem. Pelo contrário, é um tipo de membrana porosa que favorece capilarmente a circulação dos significados. Não é uma linha que circunscreve uma geografia, mas um grande traço cultural que em sua mobilidade favorece a síntese. Não é um fio fino que divide o "aqui" (o nosso) do "lá" (o deles), senão uma área instável e fluida que contém os lugares da ressignificação. Ali, as chicanas são, fundamentalmente, mediadoras, não passivas.

Se "os homens fazem as regras - argumenta Anzaldúa - as mulheres as transmitem: as mães e as sogras ensinam as jovens a obedecer, a se calar, a aceitar de forma submissa a cultura dos homens e da igreja". As discriminações naturalizadas que elas sofrem se somam à ausência de qualquer sentimento de injustiça que as alerta, de modo que cumprem um papel fundamental no funcionamento e na sobrevivência das mesmas estruturas que as tornam submissas. Dessa forma, são cumplices de um sistema patriarcal que permite e favorece costumes que talvez no fundo não desejem. Porém, precisamente esse tipo de identidade tradicional forte, que resiste ao gringo, constitui para Anzaldúa o pivô que dá espaço à mudança.

De fato, a forte cultura materna é o ponto de ancoragem da autoafirmação contraidentitária da geração mais jovem de mulheres e permite o giro linguístico (nas palavras de J. Butler), o locus que favorece o distanciamento e a crítica. Assim, a cultura "moderna" 
e "globalizada" impregna suas vidas cotidianas, ressignificando nas práticas suas cargas identitárias de etnia e de gênero, sendo precisamente esta impureza étnico-cultural o que Alzandúa ressalta. Os códigos normativos chicanos constituem a priori a história a partir da qual ressignificar e ressignificar-se, convertendo-se em um tipo de mito de origem das estratégias de autoafirmação contra-identitárias, com a vantagem secundária de erodir ao mesmo tempo pautas essenciais da vida tanto anglo-americana quanto chicana.

Em poucas palavras, Anzaldúa apresenta canais de criatividade e de ressignificação des-normatizadores, que respaldam novos significados e desarticulam os subtextos de gênero-etnia-classe. Para chicanos e gringos, em contextos nos quais as mulheres eram as guardiãs da identidade, agora são as promotoras das mudanças. Críticas do status quo, elas geram uma retórica eficaz que provoca novas afiliações e identificações, e sua apropriação seletiva de diversos registros discursivos se revela funcional para a luta por novos espaços de poder, de reconhecimento, de visibilidade e de pertencimento. Se antes dominavam a imagética cultural em termos paradigmáticos de identidade essencial, agora as mesmas mulheres por sobrecarga de identidade (em palavras de Amorós) desafiam e recusam os mandatos, constituindo-se como agentes de mudança e ressignificação - em apropriações sócio-cotidianas da lei.

\section{CRIPTOGRAFIA DA VIOLÊNCIA}

Rita Segato examina o problema da violência em vários de seus escritos. Desde os estupros aos assassinatos da Ciudad Juárez, Segato tem se preocupado em desentranhar a linguagem cifrada da violência ritual (SEGATO, 2005, 2004, 2003). Certa de que não se tratam de meros crimes sexuais, ela os interpreta como códigos que transformam o corpo das mulheres assassinadas e/ou mutiladas em mensagens cifradas que estão por decifrar. Não são alheios a esses códigos, nem à globalização, nem ao desejo insaciável de acumulação e concentração desenfreada de riquezas, porque justamente articulam ao mesmo tempo a economia monetária e a simbólica, donos do dinheiro e da vida, operam sobre um limiar normalizado de violência.

Uma rápida descrição das circunstâncias dos assassinatos que, à primeira vista, se apresentam como ininteligíveis, permite a Segato concluir que são perpetrados com excesso de crueldade. Mulheres de biotipos semelhantes apresentam evidências de estupro e outras formas de tortura. Trata-se de usar e abusar do corpo das mulheres, expropriando-o com a intenção de aniquilar o seu próprio domínio em um ato soberano alegórico. Desse modo, o assassino legisla sobre um território-corpo que é apropriado por meio de domínio soberano arbitrário e individual, , consumando simbolicamente Revista X, v. 16, n. 1, p. 224-238, 2021. 
um ato de canibalismo, físico, psicológico e moral. Nesse ato, uma mensagem cifrada é direcionada a um interlocutor, física ou mentalmente presente na cena. A mensagem é emitida sobre dois eixos de interlocução: o vertical que fala à mulher e o horizontal que se dirige aos pares. A mulher agredida/violada/assassinada se comporta como vítima sacrificial imolada em um ritual iniciático para que o agressor ocupe uma posição de reconhecimento na irmandade viril (os fratricidas, o grupo mafioso).

Segato defende que só esclarecendo o contexto de gênero se pode ter acesso à inteligibilidade suficiente desse tipo de crime e à impossibilidade do seu esclarecimento, porque, no Ocidente, a produção de masculinidade e de feminilidade se vincula à violência, cujo contexto generificado se confirma pelas regulações da vida cotidiana, naturalizando-o. Sobre essa base, o ritual sacrificial une os membros do grupo juramentado e suas vítimas - que representam um território dominado - com um vínculo inviolável. Essas vítimas são forçadas a entregar o tributo do seu corpo à coesão e à vitalidade do grupo. O sangue da vítima sela e define o pertencimento esotérico dos seus assassinos ao grupo. Se isso se dá dessa forma, como insiste Segato, é porque a violência e os códigos culturais que regulam a prática pertencem a uma mesma ordem simbólica. Trata-se, portanto, de um excesso, de uma forma exacerbada de exibicionismo no plano mafioso, mas não de fatos que instituam uma ordem simbólica de inteligibilidade diferente da que estrutura as cenas da vida cotidiana (FEMENÍAS, 2005d). Esses modos - que estão postos acima da lei - são uma advertência disciplinadora, em função de exemplaridade. Seu autor ostenta coesão, vitalidade e controle territorial sobre a rede corporativa que comanda: isto é, exerce seu poder soberano inclusive diante do Estado, ao qual desafia.

Por isso, os feminicídios se comportam como um sistema de comunicação: são mensagens, atos comunicativos violentos, cujo texto pode ser lido, interpretado e respondido no mesmo alfabeto de violência cifrada sobre os corpos das mulheres. São mensagens em uma língua franca que funciona de forma eficaz para os pertencentes do grupo. A partir disso se dá a sequência de crimes, além da ganância e do controle territorial que anunciam e a dificuldade de seu esclarecimento. A análise de Segato ilumina a lógica de muitos crimes cometidos em território latino-americano (apenas aí?). Entretanto, o mais significativo é que lança luz sobre outro aspecto do subtexto de gênero: sua capacidade de articular a violência na gramática da socialização e da cultura ocidental cotidiana.

\section{AS COMPENSAÇÕES DO HUACHO}

Sonia Montecino elaborou uma linha interpretativa original em torno da figura da mulher como mãe, que merece ser destacada como uma explicação alternativa e plausível Revista X, v. 16, n. 1, p. 224-238, 2021. 
ao modelo tipificado do machismo latino-americano (MONTECINO, 2001). Ela rastreia os modos como a tradição do culto à virgem Maria, introduzida pelos espanhóis, se consolida na cultura latino-americana até se cristalizar nas suas múltiplas aparições, como formas de materialização da identidade dos que povoam os vastos territórios do Novo Mundo. Nossa autora defende a hipótese de que, no nosso continente, a alegoria da virgem erigiu um relato fundacional, expresso em categorias vinculadas ao divino, que resolve nosso problema de origem - ser filho/a de mãe índia e pai espanhol, ou seja, mestiços - nos concedendo uma Mãe Comum, cuja epifania se constitui no que se refere à identidade simbólica e sincrética.

Efetivamente, diferente do que aconteceu com a colonização inglesa, os conquistadores espanhóis tomaram as nativas como esposas. Entendo esse aspecto de miscigenação precoce como positivo, mas ocorria - como documenta Montecino - que essas esposas (frequentemente com filhos pequenos) costumavam ser abandonadas. Muitas vezes, ao prosseguir com a conquista, os cavaleiros espanhóis deixavam para trás, nas aldeias, suas novas famílias, e não era raro que retornassem para a Espanha sem elas, ou simplesmente que morressem (batalhas, infecções, altura, etc.). Esse pai ausente cria a figura do huacho, o órfão, termo que tanto significa orfandade real como desconhecimento da identidade do progenitor masculino. Agora, o mais importante é que, tomando criticamente como referência a estrutura freudiana da personalidade, Montecino mostra de que modo a orfandade de pai (morte simbólica ou real) implicou até certo ponto a sacralização da mãe institucionalizada pela figura de Maria. A ausência da figura masculina instituiu a mulher-mãe no centro único da cena, dotando-a de caracteres onipotentes: Maria secularizada e entronada.

Assim, a figura da mulher-mãe onipresente marca a identidade de homens e mulheres latino-americanos, gerando nos primeiros a necessidade de condutas compensatórias (defensivas) diante da onipresença feminina. A ausência simbólica do pater, no imaginário mestiço da América Latina, é substituída por modelos exacerbados de masculinidade, figuras poderosas e violentas: o caudilho, o guerrilheiro, o militar. As circunstâncias históricas da conquista e da colonização favoreceram - defende Montecino - o surgimento do fenômeno dos inumeráveis cultos à virgem Maria e, por extensão, das santas locais. Mas também gerou secularizações substitutivas como a mamãe do tango rio-platense, o que favorece a ativa participação e a visibilidade das mulheres no espaço público. Sua outra face é o tão referido machismo latino-americano. 


\section{ATRAVESSANDO O GÊNERO}

Graças à denominada "estrutura da alienação", Marie Ramos Rosado resgata a presença histórica do/as negro/as em Porto Rico (LAVOU ZOUNGBO, 2003, p. 289). Enquanto que, por razões étnicas, eles constituíram uma alteridade radical, um "estrangeirismo inquietante", no geral as políticas dos Estados da América Latina se estruturaram (e ainda o fazem) a partir da supremacia branca, da inviabilização dos negros e dos povos originários e da ideologia de "melhoramento da raça" em termos de "branqueamento" da sociedade ibero-americana. Sobre um passado de escravidão, do qual foram se emancipando em diferentes períodos do século XIX, pouco se sabe em geral dos itinerários das populações negras, para além de certo estereótipo "exótico" da costumeira divulgação de Porto Rico como um paraíso turístico. Sabe-se menos ainda da história e da situação das mulheres negras onde a estrutura econômica escravista se prolongou mais além do escravismo legal (RAMOS ROSADO, 2005), tanto a respeito de seu próprio grupo étnico-cultural quanto de sua relação com as mulheres brancas, com clara supremacia social, ainda que nem sempre política.

Marie Ramos Rosado nos introduz no terreno da indagação das representações literárias da população negra caribenha, em especial das mulheres, e das dificuldades técnicas e metodológicas enfrentadas por aqueles que querem reconstruir sua história. Nesses casos, a "igualdade" proclamada se tornou um processo de invisibilidade (quando não de subjugação) da diferença étnica e cultural, em que a não confirmação "do outro" implicou brutalmente a negação da sua "identidade" e da sua personalidade. Ramos Rosado remete a problemas como a dupla lealdade de etnia e de gênero (amplamente desenvolvida pelo feminismo afro-estadunidense) ou às formas de subordinação das mulheres negras em comparação com os homens de sua própria etnia, mas também das mulheres brancas com cuja solidariedade de "sexo" era impossível contar para além de situações isoladas ou de proclamações retóricas.

Tal como está constituído o tecido social da maioria dos países da América Latina, a submissão dos conjuntos étnicos-culturais ao modelo "branco" é prioritária, e qualquer outra subordinação passa a um segundo plano, potencializada pela equação cor-pobreza-exclusão. Porque, inclusive quando há poder aquisitivo, o fator etnia gera mecanismos de exclusão ou desqualificação que poucas vezes pode reverter a capacidade econômica. Só compreendendo essa somatória é que algumas complexas situações de marginalidade, que não são econômicas senão simbólicas, podem ser entendidas. Como aponta Ramos Rosado, o reconhecimento de que a sociedade atual (não apenas em Porto 
Rico) está fundada sobre três raízes - a espanhola, a indígena e a negra - e que por razões econômicas e sociais tem sido dada visibilidade somente a uma delas, implicou um impacto intelectual na sociedade, fazendo com que o "tema negro" adquirisse afirmação, visibilização e reconhecimento. Sem reconhecer o papel desempenhado pelas relações entre a população masculina branca e a submissão da população masculina negra através de suas mulheres, é impossível explicar demograficamente o crescimento populacional da mestiçagem na América Latina. Só lendo o subtexto de gênero com seus duplos critérios morais se revela boa parte da história do continente.

Uma vez mais, as conceitualizações que têm como base um modelo de sociedade dimórfica (homem-mulher) se veem desafiadas pela transversalidade da etnia, destacada por trabalhos como o de Marie Ramos Rosado. O que tem acontecido, então, com os estudos e pesquisas em torno das mulheres negras? Como aponta nossa autora, a maior parte das pesquisas acerca do "tema negro" se limita somente a mencionar essas mulheres. Diferente do trabalho desempenhado pelas afro-americanas estadunidenses, ainda não foram realizados estudos suficientes sobre a realidade em que vivem as mulheres negras porto-riquenhas ou as negras da América Latina em geral, e sobre a sua história. A razão para que isso ocorra não é apenas de índole histórica, mas também política, econômica, social e cultural: o reconhecimento das contribuições da cultura negra para a formação das nações nunca integrou uma agenda política. Além disso, não houve, até recentemente, um processo de escrita da autoconsciência da negritude, que muitas vezes, por temor à discriminação, mais se ocultou do que se proclamou.

A partir do exposto temos, segundo Ramos Rosado, que as mulheres negras tampouco se constituíram em um grupo diferenciado. No entanto, sendo feito um estudo historicamente comparativo encontraríamos - como aponta Ramos Rosado - que as mulheres negras têm contribuído para a sociedade porto-riquenha. Perguntas como "que função desempenha o racismo em nossa sociedade neocolonial capitalista e qual é o lugar das mulheres negras como (re)produtoras de modelos em uma sociedade que se autoidentifica como multiétnica?”, estão tencionadas para além da distinção sexo-gênero, ainda que a perspectiva de gênero ilumine a dinâmica.

\section{PARA FINALIZAR}

Sem pretensões de esgotar o tema, tratei de esboçar um panorama esquemático daquelas que considero algumas das maiores contribuições das elaborações feministas latino-americanas, de modo a fornecer respostas rápidas ao desafio lançado no começo. Acredito poder sustentar, com suficiente fundamento, que o feminismo na América Revista X, v. 16, n. 1, p. 224-238, 2021. 
Latina apresenta características e contribuições próprias que o fazem merecer interesse especial. Surge a partir de narrativas múltiplas e tradições diversas que incluem ab initio transversalidades de classe, etnia, gênero e religião alheias a outros contextos. A recepção precoce, tradução (a nossa é uma sorte de situação constante de hermeneuta/tradutor), discussão e reapropriação de teorias - desde o Iluminismo à pós-modernidade - tem dado lugar a uma série de triangulação, ou locus catalizador, que atua como filtro e caixa de ressonância de conceitualizações e práticas inovadoras que constituem uma real contribuição para o feminismo, e não apenas para nós mesmas.

\section{REFERÊNCIAS}

AMORÓS, C. "Revolución Francesa y Crisis de Legitimidad Patriarcal" In: Hiparquia, Buenos Aires: AAMEF, 1996.

ANZALDÚA, G. Borderlans/La frontera, San Francisco: Aunt Lute Books, 1987.

APONTE SÁNCHEZ. E. "La Revolución Bolivariana de Venezuela y las Mujeres" In: FEMENÍAS, M. L. Perfiles del Pensamiento Iberoamericano, 2. Buenos Aires: Catálogos, 2005a.

BATTICUORE, G. El taller de la escritora. Veladas literarias de Juana Monuela Gorriti. Rosario: Beatriz Viterbo, 1999.

BATTICUORE, G. La mujer romántica. Buenos Aires: Edhasa, 2005.

BIDEGAIN, A.M. e Ospina, M.A. "Resistencia y resiliencia: las organizaciones de mujeres ante la crisis colombiana actual", In: FEMENÍAS, M. L. Perfiles del Pensamiento Iberoamericano, 2. Buenos Aires: Catálogos, 2005a.

DOMÍNGUEZ, N. "La toma de la palabra”. In: FEMENÍAS, M. L. Aportes del feminismo Iberoamericano. Montevidéu: Centro Cultural España, nov. 15, 2005 b.

FEMENÍAS, M. L. Perfiles del feminismo iberoamericano, 1. Buenos Aires: Catálogos, 2002a.

FEMENÍAS, M. L. "El feminismo latinoamericano ante el desafío de las diferencias" In: Debots, 76. Primavera, 2002b.

FEMENÍAS, M. L. Perfiles del Pensamiento Iberoamericano, 2. Buenos Aires: Catálogos, 2005a. 
FEMENÍAS, M. L. “Aportes del feminismo Iberoamericano”. Montevidéu: Centro Cultural España, nov. 15, 2005 b.

FEMENÍAS, M. L. "Feminismos en Argentina" In: Lobrys, 9, 2005c. Disponível em: www.unb.br/ih/his/gefem/

FEMENÍAS, M. L. “Apuntes sobre la violencia contra las mujeres” In: Debots, 89. Verão, 2005d.

FOUCAULT, M. Arqueología del saber. Buenos Aires: Siglo XXI, 1976.

IGLESIA, C. (comp.). El ajuar de lo patria. Buenos Aires: Feminaria, 1993.

LAVOU ZOUNGBO, V. Du "Migrant nu” au citoyen différé. Presses Universitaires de Perpignan: 2003.

LIMA COSTA, Claudia de. "Repensando el género: tráfico de teorías en las Américas". In: FEMENÍAS, María Luisa. Perfiles del feminismo iberoamericano. Buenos Aires: Catálogos, 2002. p. 189-214.

MANSO, Juana. Album de Señoritas. Buenos Aires, 1854.

MASIELO, F. Lo mujer y el espacio público. Buenos Aires: Feminaria, 1994.

MONTECINO, S. Madres y Huochos. Santiago de Chile: Sudamericana, 2001.

OLIVER, A. "El feminismo compensatorio de Vaz Ferreira" In: In: FEMENÍAS, María Luisa. Perfiles del feminismo iberoamericano. Buenos Aires: Catálogos, 2002.

RAMOS ROSADO, M. "La mujer negra en la literatura puertorriqueña” In: FEMENÍAS, M. L. Perfiles del Pensamiento Iberoamericano, 2. Buenos Aires: Catálogos, 2005a.

ROSENDE, Petrona. La Aljaba. Buenos Aires: 1830.

SANTA CRUZ, M.I. "Sobre el concepto de igualdad: algunas observaciones" In: Isegaría, 6. Coordenada por Célia Amorós Puente, 1992.

SCHUTTE, O. Cultural identity and social liberation in Lotin American thought. Albany: SUNY Press, 1993.

SEGATO, R. Las estructuras elementales de la violencia, Bemal: UNQui-Prometeo, 2002. 
SEGATO, R. Antropología y Derechos Humanos: Alteridad y Ética en el movimiento de los Derechos Universales, Universidade de Brasilia, Departamento de Antropología, 2004.

SEGATO, R. Antropología y Derechos Humanos: Alteridad y Ética en el movimiento de los Derechos Universales, Universidade de Brasília, Departamento de Antropologia, 2003.

SEGATO, R. "Territorio, soberanía y crímenes de segundo estado: la escritura en el cuerpo de las mujeres asesinadas en Ciudad Juárez" In: FEMENÍAS, M. L. Perfiles del Pensamiento Iberoamericano, 2. Buenos Aires: Catálogos, 2005a.

ZANETTI, S. Sor Juana Inés de a Cruz. Primero Sueño y otros textos. Buenos Aires, Losada, 1995. 